\title{
Increased Biosynthesis of Vasoactive Prostanoids in Schönlein-Henoch Purpura
}

\author{
BURKHARD TÖNSHOFF, RITA MOMPER, HORST SCHWEER, KARL SCHÄRER, AND \\ HANNSJÖRG W. SEYBERTH \\ Children's Hospital, University of Heidelberg, Heidelberg, Germany [B.T., R.M., K.S.] and Children's Hospital, \\ University of Marburg, Marburg, Germany [H.S., H.W.S.]
}

\begin{abstract}
Schönlein-Henoch purpura (SHP) is an acute immune-mediated vasculitis characterized by infiltration of polymorphonuclear leukocytes into the vessel wall causing damage to the vascular endothelium by the release of proteolytic enzymes. The local inflammatory and thrombotic process may be regulated by increased biosynthesis of vasoactive prostanoids. We investigated the biosynthesis of thromboxane $A_{2}\left(T x A_{2}\right)$, a potent vasoconstrictor and platelet agonist, prostacyclin $\left(\mathrm{PGI}_{2}\right)$, a vasodilator and platelet antagonist, and prostaglandin $\mathrm{E}_{2}$, a mediator of inflammation, in 14 children with SHP by physicochemical analysis of index metabolites in plasma and urine. $\operatorname{TxA}_{2}$ and $\mathrm{PGI}_{2}$ biosynthesis in the systemic circulation was significantly elevated in the acute phase of the disease and correlated with the degree of clinical symptoms. Recurrent episodes of the disease were associated with phasic increases of plasma and urinary $\mathbf{T x A _ { 2 }}$ and $\mathrm{PGI}_{2}$ metabolites. Renal TxA formation was highest in two patients presenting with the nephrotic syndrome and extracapillary glomerulonephritis. Prostaglandin $\mathbf{E}_{2}$ biosynthesis in the systemic circulation was increased in the acute phase of the disease. The enhanced $\mathrm{TxA}_{2}$ formation is consistent with phasic platelet activation in SHP. The increased PGI $_{2}$ biosynthesis reflects endothelial cell damage and may be a response of vascular endothelium to modulate plateletvessel wall and leukocyte-vessel wall interactions. Increased prostaglandin $E_{2}$ formation, which probably derives from activated polymorphonuclear leukocytes and macrophages, is thought to be related to the inflammatory process in SHP. (Pediatr Res 32: 137-140, 1992)
\end{abstract}

\section{Abbreviations}

SHP, Schönlein-Henoch purpura

$\mathrm{PGE}_{2}$, prostaglandin $\mathrm{E}_{2}$

PGE-M, $7 \alpha$-hydroxy-5,11-diketo-tetranor-prostane-11, 16-dioic acid

$\mathbf{P G I}_{2}$, prostacyclin

$\operatorname{TxA}_{2}$, thromboxane $A_{2}$

$\mathrm{TxB}_{2}$, thromboxane $\mathrm{B}_{2}$

2,3-dinor- $T \mathrm{XB}_{2}$, 2,3-dinor-thromboxane $\mathbf{B}_{2}$

11-dehydro-T $\mathrm{XB}_{2}$, 11-dehydro-thromboxane $\mathrm{B}_{2}$

6-keto-PGF $F_{1 a}$, 6-keto-prostaglandin $F_{1 \alpha}$

2,3 dinor-6-keto-PGF ${ }_{1 a}, 2,3$-dinor-6-keto-prostaglan$\operatorname{din} \mathbf{F}_{1 \alpha}$

Received April 29, 1991; accepted February 27, 1992

Correspondence and reprint requests: Dr. B. Tönshoff, University Children's Hospital, Im Neuenheimer Feld 150, D-6900 Heidelberg, Germany.

Supported by grants from the Deutsche Forschungsgemeinschaft (SE 263/8 and 263/9).
SHP is the most common form of vasculitis in children (1). The vasculitis is initiated by the subendothelial deposition of $\mathrm{IgA} / \mathrm{IgG}$ immune complexes in small blood vessels (2). Complement activation induces infiltration of polymorphonuclear leukocytes, which by the release of proteolytic enzymes cause damage to the vessel wall with secondary thrombosis and hemorrhage (3). The altered integrity of the vascular endothelium is likely to involve changes in prostanoid biosynthesis at the platelet vascular interface. $\mathrm{TxA}_{2}$, the major cyclooxygenase product of arachidonic acid in platelets, is a potent platelet aggregator and vasoconstrictor (4). The potential pathophysiologic role of $\mathrm{TxA}_{2}$ in acute immune-mediated vasculitic disorders has not yet been elucidated.

In the present study, we investigated $\mathrm{TxA}_{2}$ biosynthesis in children with SHP prospectively during the disease process. To avoid sampling and analytical problems, $\mathrm{TxA}_{2}$ biosynthesis was examined by a highly specific and sensitive method, which measures two major urinary enzymatic metabolites, 11-dehydro$\mathrm{TxB}_{2}$ and 2,3-dinor- $\mathrm{TxB}_{2}$, which are index metabolites of $\mathrm{TxA}_{2}$ activation in the systemic circulation $(5,6)$, and by measuring urinary $\mathrm{TxB}_{2}$, which predominantly reflects renal $\mathrm{Tx} \mathrm{A}_{2}$ formation (7). In addition, circulating TxA $\mathrm{A}_{2}$ levels were estimated by determination of plasma 11-dehydro- $\mathrm{TxB}_{2}$, the most abundant enzymatic metabolite of $\mathrm{TxB}_{2}(6,8)$.

Another prostanoid that may modulate the function of the altered endothelium in SHP is $\mathrm{PGI}_{2}$, the major cyclooxygenase product of arachidonic acid in vascular endothelium, with potent vasodilative and antiaggregatory properties (9). $\mathrm{PGI}_{2}$ biosynthesis was assessed by use of a highly specific, noninvasive method. This is the measurement of its urinary metabolite 2,3-dinor-6keto-PGF ${ }_{1 a}$ as an index of systemic $\mathrm{PGI}_{2}$ formation (10) and measurement of 6-keto-PGF ${ }_{1 a}$, which is derived predominantly from the kidney (7). In parallel, the biosynthesis of $\mathrm{PGE}_{2}$, a putative mediator of inflammation with vasodilative and permeability increasing properties (11), was examined by measuring its urinary metabolite, PGE-M, as an index metabolite of systemic $\mathrm{PGE}_{2}$ activity (12).

\section{MATERIALS AND METHODS}

Patients and study design. Fourteen children (four girls and 10 boys), aged 2.5 to 16 (median 6) y, were studied. All had the typical cutaneous manifestations of SHP and joint symptoms; eight patients had gastrointestinal involvement and seven patients had renal involvement with microhematuria and proteinuria. Two patients developed the nephrotic syndrome with impaired renal function. In the latter two patients, renal biopsy showed diffuse extracapillary glomerulonephritis with $100 \%$ cellular crescents and endo/extracapillary glomerulonephritis with $100 \%$ cellular crescents, respectively. By immunofluorescence, both biopsies contained granular deposits of IgA in the glomerular mesangium.

Patients who had taken aspirin or other cyclooxygenase inhib- 
itors in the preceding $10 \mathrm{~d}$ were excluded. Patients were prospectively assessed by their attending physicians according to a clinical score (Table 1) to quantitate the severity of their extrarenal organ involvement. Patients with a clinical score $>2$ (algebraic sum of the three organ involvements) were assigned to the acute phase; the recovery phase was defined as the absence of any extrarenal symptoms of SHP (clinical score $=0$ ).

On admission, blood was obtained for determination of plasma 11-dehydro- $\mathrm{TxB}_{2}$. Subsequent blood samples were taken serially every 3rd day. Simultaneously, urine was collected during $24 \mathrm{~h}$ from admission until discharge from the hospital. Total urine output was determined and aliquots were stored at $-80^{\circ} \mathrm{C}$ for analysis of prostanoids. To examine the association between clinical activity and prostanoid activity, the severity of clinical involvement was quantified by a score related to skin, joint, and intestinal manifestations (Table 1). The plasma and urine samples obtained in the presence of most severe clinical symptoms (i.e. with the highest algebraic sum of the three extrarenal organ involvements) were compared with those obtained in the recovery phase and with controls (12 age- and sex-matched healthy children). Informed consent was obtained from each child's parent(s) before entry into the study. The protocol was approved by the Ethics Committee of the University of Heidelberg.

Analytical methods. For the analysis of urinary and plasma prostanoids, gas chromatographic mass spectrometric methods were used, which have been described previously (13). Following the principle of stable isotope assays, endogenous prostanoids were quantitated against their respective deuterated analogues, which were added as internal standards at the beginning of the procedure. The determination of 6-keto-PGF $\mathrm{PG}_{1 \mathrm{a}}$ involved extraction by octadecyl silica and normal phase silica cartridges, purification by HPLC, derivatization to the methylester-methoximetrimethylsilylethers, and quantitation by capillary gas chromatography mass spectrometry in the electron impact mode (13). The 2,3-dinor-6-keto-PGF Ia $_{1}$ was purified by extraction and back extraction under alkaline and acidic conditions and thin-layer chromatography. The pentafluorobenzylester-methoxime-trimethylsilyether derivative was analyzed by gas chromatography mass spectrometry in the negative ion chemical ionization mode (13). The 2,3-dinor- $\mathrm{TxB}_{2}$ and $\mathrm{TxB}_{2}$ were extracted chemoselectively by phenylboronic acid columns, purified by thin-layer chromatography, derivatized, and quantitated in analogy to 2,3dinor-6-keto-PGF ${ }_{1 a}$ (13). The 11-dehydro- $\mathrm{TxB}_{2}$ was extracted from plasma and urine by octadecyl silica cartridges, purified by thin-layer chromatography, and analyzed as the pentafluorobenzylester-trimethylsilylether by gas chromatography-tandem mass spectrometry as described previously (6). PGE-M was extracted as the methoxime by ethyl acetate/hexane, derivated to the pentafluorobenzylester, purified by thin-layer chromatography, the trimethylsilylether was formed, and PGE-M was quantified by gas chromatography-tandem mass spectrometry. Analyses of creatinine in serum and urine were performed by routine laboratory methods.

Prostanoid excretion rates were expressed as $\mathrm{ng} / \mathrm{h} / 1.73 \mathrm{~m}^{2}$ calculated per $100 \mathrm{~mL}$ glomerular filtration rate (creatinine clearance) to correct for the influence of different degrees of

Table 1. Clinical scores to assess degree of extrarenal organ involvement during acute phase of SHP

\begin{tabular}{ll}
\multicolumn{2}{c}{ involvement during acute phase of SHP } \\
\hline Organ & \multicolumn{1}{c}{ Degree of severity } \\
\hline Skin & $=$ no symptoms \\
& $=$ sporadic petechiae \\
2 & $=$ widespread purpura \\
& $0=$ no symptoms \\
1 & $=$ arthralgia in a single joint \\
Joints & $2=$ arthralgia in several joints \\
& $0=$ no symptoms \\
Gastrointestinal & $1=$ abdominal pain with occult melaena \\
tract & $2=$ hemorrhagic colitis \\
\end{tabular}

glomerular function on prostanoid excretion. A previous report had established a close positive correlation between prostanoid excretion and glomerular filtration rate in chronic renal failure (14).

Significant differences between the data were evaluated by the Wilcoxon signed rank-test for paired data or by the MannWhitney test where appropriate. $p<0.05$ was accepted as being statistically significant. Associations between variables were investigated by linear regression analysis.

\section{RESULTS}

Plasma levels of 11-dehydro- $\mathrm{TxB}_{2}$ and peak urinary excretion rates of 11-dehydro- $\mathrm{TxB}_{2}$ and 2,3-dinor- $\mathrm{TxB}_{2}$ were significantly elevated in the acute phase of SHP compared to the recovery phase and to the control group (Table 2). Excretion of 11dehydro- $\mathrm{TxB}_{2}$ was almost twice that of 2,3 -dinor- $\mathrm{TxB}_{2}$ in the acute phase and dropped in parallel in the recovery phase to reach similar values as in controls. Urinary 11 -dehydro- $\mathrm{TxB}_{2}$ and 2,3-dinor- $\mathrm{TxB}_{2}$ excretion were correlated $(r=0.57 ; p<$ $0.001)$. $\mathrm{TxB}_{2}$ excretion was increased in the acute phase, but in contrast to the index metabolites of systemic Tx activity it did not significantly differ between acute and recovery phase (Table 2 ). However, there was a persistently high $\mathrm{TxB}_{2}$ excretion in the recovery phase of the two patients with nephrotic syndrome and histologically proven glomerulonephritis $(20.9$ and $28.5 \mathrm{ng} / \mathrm{h} /$ $1.73 \mathrm{~m}^{2}$ ) compared to that of the other 12 patients (median 10.2; range $4.9-19.8 \mathrm{ng} / \mathrm{h} / 1.73 \mathrm{~m}^{2}$ ).

Concomitant with the enhanced systemic $\mathrm{TxA}_{2}$ formation, $\mathrm{PGI}_{2}$ biosynthesis was increased in the acute phase as assessed by the urinary excretion rate of 2,3-dinor-6-keto-PGF ${ }_{1 a}$ (Table $2)$. This was significantly correlated with 11 -dehydro- $\operatorname{TxB}_{2}(r=$ $0.72 ; p<0.001)$ and 2,3-dinor- $\mathrm{TxB}_{2}(r=0.56 ; p<0.005)$ in the acute phase. In contrast, urinary excretion of 6-keto-PGF Ia $_{1 \mathrm{a}}$ in the acute phase did not differ significantly from that in the recovery phase and from controls. A significant correlation was found between the algebraic sum of the clinical scores and plasma 11 -dehydro- $\mathrm{TxB}_{2}(r=0.54 ; p<0.01)$, urinary 11 -dehydro- $\mathrm{TxB}_{2}$ $(r=0.69 ; p<0.0001)$ (Fig. 1), urinary 2,3-dinor-TxB ${ }_{2}(r=0.62$; $p<0.001)$, and 2,3-dinor-6-keto-PGF ${ }_{1 \mathrm{a}}(r=0.64 ; p<0.0005)$. PGE-M excretion rates in the acute phase were significantly higher $(p<0.01)$ than during recovery (Table 2$)$.

\section{DISCUSSION}

This study demonstrates increased systemic $\mathrm{TxA}_{2}$ formation in the acute phase of patients with SHP that normalizes during recovery from the disease. $\mathrm{TxA}_{2}$ biosynthesis was assessed by specific measurement of indexes of the two major pathways of $\mathrm{TxA}_{2}$ metabolism in the systemic circulation, 11-dehydro- $\mathrm{TxB}_{2}$ and 2,3-dinor- $\operatorname{TxB}_{2}(15,16)$.

The measurement of urinary metabolites has the advantage of being noninvasive and representing time-integrated indexes of $\mathrm{TxA}_{2}$ biosynthesis (17). As in healthy controls (6) and in conditions with increased platelet-vessel wall interaction $(14,15)$, the endogenous urinary 11-dehydro- $\mathrm{TxB}_{2}$ excretion rates exceeded those of endogenous urinary 2,3-dinor- $\mathrm{TxB}_{2}$ in the patients with SHP indicating that 11-dehydro- $\mathrm{TxB}_{2}$ is the more abundant urinary $\mathrm{TxA}_{2}$ metabolite. The combined analysis of both the 2,3dinor and the 11-dehydro metabolites permits us to rule out that increased excretion of one metabolite reflects just a shift in the metabolic disposition of $\mathrm{TxA}_{2}$ and not a true increased $\mathrm{TxA}_{2}$ biosynthesis. The high plasma concentration of the major enzymatic metabolite of $\mathrm{TxA}_{2}, 11$-dehydro- $\mathrm{TxB}_{2}$, in the acute phase supports our hypothesis of an exaggerated $\mathrm{TxA}_{2}$ synthesis in SHP.

Because thrombocytes are the major source of $\mathrm{TxA}_{2}$ in humans (4), the increased $\mathrm{TxA}_{2}$ formation can be attributed primarily to platelet activation. Vascular endothelium and macrophages may contribute to a small extent to enhanced $\mathrm{TxA}_{2}$ formation. In an 


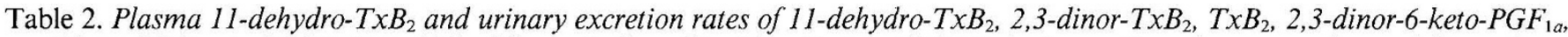
6-keto-PGF $F_{1 a}$, and PGE-M in 12 healthy controls and in 14 patients with SHP during acute and recovery phase of disease*

\begin{tabular}{|c|c|c|c|}
\hline \multirow[b]{2}{*}{ Variable } & \multirow[b]{2}{*}{$\begin{array}{c}\text { Controls } \\
\left(\mathrm{ng} / \mathrm{h} / 1.73 \mathrm{~m}^{2}\right)\end{array}$} & \multicolumn{2}{|c|}{ SHP } \\
\hline & & $\begin{array}{c}\text { Acute phase } \\
\left(\mathrm{ng} / \mathrm{h} / 1.73 \mathrm{~m}^{2}\right)\end{array}$ & $\begin{array}{l}\text { Recovery phase } \\
\left(\mathrm{ng} / \mathrm{h} / 1.73 \mathrm{~m}^{2}\right)\end{array}$ \\
\hline Plasma 11-dehydro- $\mathrm{TxB}_{2}$ & $\begin{array}{c}8.3 \\
(2.4-12.3)\end{array}$ & $\begin{array}{c}29.8+\div \\
(2.0-95.7)\end{array}$ & $\begin{array}{c}9.5 \\
(1.7-17.6)\end{array}$ \\
\hline Urinary 11-dehydro- $\mathrm{TxB}_{2}$ & $\begin{array}{c}30.7 \\
(3.5-65.1)\end{array}$ & $\begin{array}{c}113.9 \$ \| \\
(14.6-547.3)\end{array}$ & $\begin{array}{c}22.1 \\
(0.8-39.3)\end{array}$ \\
\hline Urinary 2,3-dinor- $\mathrm{TxB}_{2}$ & $\begin{array}{c}14.4 \\
(6.2-37.6)\end{array}$ & $\begin{array}{c}60.9 \S \| \\
(15.3-338.2)\end{array}$ & $\begin{array}{c}16.2 \\
(6.7-30.7)\end{array}$ \\
\hline Urinary $\mathrm{TxB}_{2}$ & $\begin{array}{c}2.3 \\
(0.8-10.1)\end{array}$ & $\begin{array}{c}12.6 \div \\
(3.0-106.1)\end{array}$ & $\begin{array}{c}13.39 \\
(3.5-28.5)\end{array}$ \\
\hline Urinary 2,3-dinor-6-keto-PGF ${ }_{1 a}$ & $\begin{array}{c}7.4 \\
(3.9-10.1)\end{array}$ & $\begin{array}{c}17.6 \|^{* *} \\
(6.0-58.4)\end{array}$ & $\begin{array}{c}7.3 \\
(3.6-14.9)\end{array}$ \\
\hline Urinary 6-keto-PGF & $\begin{array}{c}4.5 \\
(1.0-13.2)\end{array}$ & $\begin{array}{c}6.2 \\
(1.0-79.8)\end{array}$ & $\begin{array}{c}3.1 \\
(1.8-7.4)\end{array}$ \\
\hline PGE-M & $\begin{array}{c}219 \\
(72-484)\end{array}$ & $\begin{array}{c}586^{* *+\dagger \dagger} \\
(150-2842)\end{array}$ & $\begin{array}{l}204 \\
(79-388)\end{array}$ \\
\hline
\end{tabular}

* Prostanoid excretion rates were standardized for $100 \mathrm{~mL}$ glomerular filtration rate. Values are given as median and range.

$\dagger p<0.05$, acute phase $v s$ recovery.

$\$ p<0.05$, acute phase vs controls.

$\S p<0.005$, acute phase $v s$ recovery.

$\| p<0.001$, acute phase $v s$ controls.

If $p<0.05$, recovery $v s$ controls.

$* * p<0.01$, acute phase $v s$ recovery.

$\dagger \dagger p<0.005$, acute phase $v s$ controls.

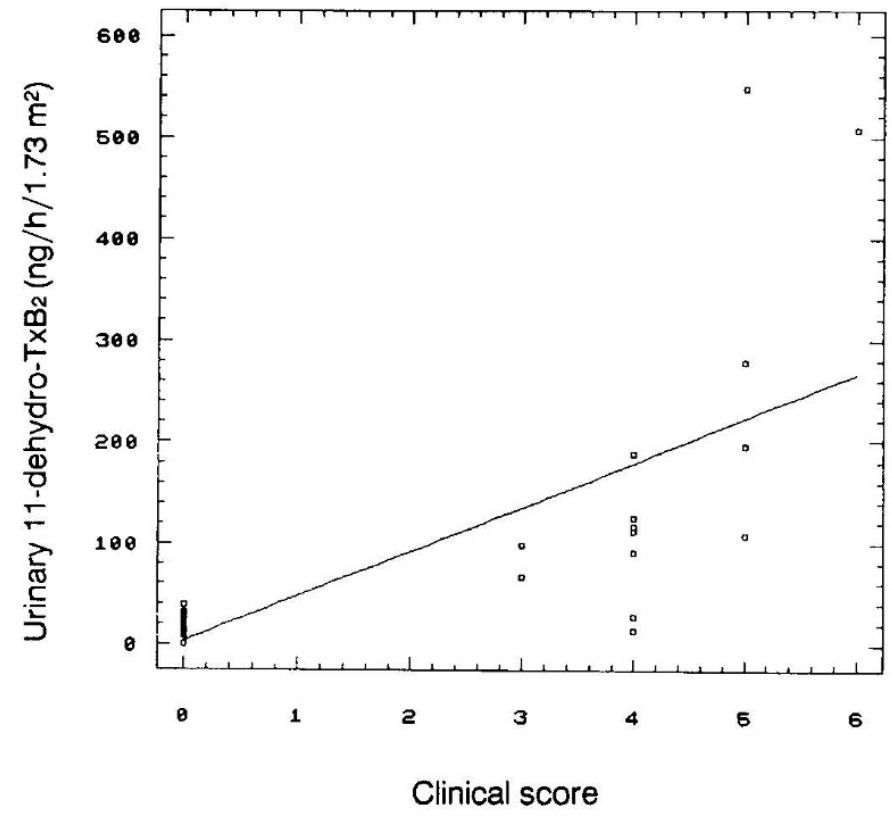

Fig. 1. Correlation of urinary 11-dehydro-TxB $\mathrm{B}_{2}$ with the highest algebraic sum of the clinical scores in 14 children with SHP during the acute phase of the disease and recovery $(r=0.69 ; p<0.0001)$.

animal model of immune complex vasculitis, platelet accumulation was demonstrated at skin sites in reversed passive Arthus reactions (18), supporting the concept that increased $\mathrm{TxA}_{2}$ formation reflects platelet activation in SHP representing a model of immune complex vasculitis in humans. The close temporal relation between clinical activity and systemic $\mathrm{TxA}_{2}$ formation (Fig. 1) indicates phasic platelet activation during episodes of active disease. Other methods to investigate platelet function, such as measurement of $\beta$-thromboglobulin and platelet factor 4 , were not obtained in this study because of technical factors stimulating platelet activation artifactually during blood sampling, especially in young children.
Renal $\mathrm{TxB}_{2}$ formation was investigated in our study by measuring the urinary excretion rates of the $\mathrm{TxA}_{2}$ hydration product $\mathrm{TxB}_{2}$. This predominantly reflects renal $\mathrm{TxA} \mathrm{A}_{2}$ activity when concomitant extrarenal $\mathrm{TxA} \mathrm{A}_{2}$ stimulation is excluded (7). It is of interest that renal $\mathrm{TxA}_{2}$ excretion was higher in two patients with glomerulonephritis and nephrotic syndrome compared to the other cases. It is noteworthy that patients with lupus nephritis, another form of renal vasculitis, present increased urinary $\mathrm{TxB}_{2}$ excretion, which correlates with the degree of glomerular injury (19). Pharmacologic intervention with a selective $\mathrm{TxA}_{2}$ antagonist significantly improved renal function in this situation (20). Accordingly, the investigation of renal $\mathrm{TxA}_{2}$ formation in patients with SHP nephritis should be pursued.

In addition to an increased $\mathrm{TxA}_{2}$ formation, the present study demonstrates enhanced $\mathrm{PGI}_{2}$ formation in patients with SHP. This prostanoid is the principal metabolite of arachidonic acid produced by vascular endothelium and has potent vasodilator and platelet antiaggregatory effects (9). Under physiologic conditions, its circulating blood concentration is too low to exert a biologic effect, but platelet-inhibitory concentrations are formed at the site of vessel injury to limit the degree of platelet activation (21). Because $\mathrm{PGI}_{2}$ formation in our patients was positively correlated to $\mathrm{TxA}_{2}$ formation, it is possible that increased endothelial $\mathrm{PGI}_{2}$ biosynthesis is a response of vascular endothelium to compensate for $\mathrm{TxA}_{2}$-mediated platelet activation and does not merely reflect damage to the endothelium. Endothelial cell $\mathrm{PGI}_{2}$ is also thought to influence leukocyte/vessel wall interactions by blocking leukocyte adhesion after stimulation (22). It has been demonstrated that $\mathrm{PGI}_{2}$ synthesis in vascular cells can be induced by platelet activating factor (23) and IL-1 (24), which are both stimulated in immune-mediated vascular disorders $(25$, 26). Thus, increased $\mathrm{PGI}_{2}$ formation in SHP may not only regulate local thrombotic events but also modulate the inflammatory processes.

A previous study has reported decreased $\mathrm{PGI}_{2}$ stimulating activity ex vivo in children with SHP (27). In contrast, the present study demonstrates that the in vivo $\mathrm{PGI}_{2}$ biosynthesis is increased in the acute phase of SHP. A similar discrepancy between in vivo and ex vivo $\mathrm{PGI}_{2}$ production has also been observed in hemolyticuremic syndrome (14) and may be explained by the fact that 
measurement of ex vivo $\mathrm{PGI}_{2}$ stimulating activity, in contrast to $\mathrm{PGI}_{2}$-metabolite excretion rates, does not reflect the actual biologically effective activity of $\mathrm{PGI}_{2}$ in vivo.

The elevated systemic $\mathrm{PGE}_{2}$ production found in our study, which probably derives from activated polymorphonuclear leukocytes and macrophages, may be related to the inflammatory process observed in SHP. $\mathrm{PGE}_{2}$ is known to be a mediator of inflammation by promoting blood flow in the inflamed region and thus enhancing edema formation and leukocyte infiltration (28). On the other hand, $\mathrm{PGE}_{2}$ has a local immunosuppressive effect by inhibiting lymphocyte transformation due to mitogen stimulation, antibody production, and lymphokine production. Therefore, it is difficult to assess whether local $\mathrm{PGE}_{2}$ production enhances or suppresses the inflammatory process in SHP.

In conclusion, this study demonstrates increased $\mathrm{TxA}_{2}$ and $\mathrm{PGI}_{2}$ biosynthesis in children with SHP as a model of immunemediated vasculitis consistent with increased platelet-vessel wall and leukocyte-vessel wall interaction in the disease process. Increased $\mathrm{TxA}_{2}$ and $\mathrm{PGI}_{2}$ formation have been reported in other diseases with increased platelet vessel wall interaction such as severe atherosclerosis (15), unstable coronary heart disease (29), and systemic sclerosis with Raynaud's phenomenon (30) as models of chronic degenerative vasculopathy and in hemolyticuremic syndrome (14) as a model of acute toxic vasculopathy. The similarity of these findings suggests that although damage to the vascular endothelium may result from a variety of insults the response of the vascular endothelium is rather uniform.

Acknowledgments. The authors thank Karin Soeding and Dorothee Huckle for their technical assistance.

\section{REFERENCES}

1. Golitz LE 1986 The vasculitides and their significance in the pediatric age group. Dermatol Clin 4:117-125

2. Wenner NP, Safai B 1983 Circulating immune complexes in Henoch-Schönlein purpura. Int J Dermatol 22:383-385

3. Christian C, Sergent J 1976 Vasculitis syndromes: clinical and experimental models. Am J Med 61:385-392

4. FitzGerald GA, Oates JA, Hawiger J, Maas RL, Roberts LJ, Lawson JA, Brash AR 1983 Endogenous synthesis of prostacyclin and thromboxane and platelet function during chronic administration of aspirin in man. $\mathbf{J}$ Clin Invest 71:676-688

5. Lawson JA, Brash AR, Doran J, FitzGerald GA 1986 Long-lived enzymatic metabolites of thromboxane $\mathrm{B}_{2}$ in the human circulation. Anal Biochem $155: 198-205$

6. Schweer H, Meese CO, Furst O, Kuhl PG, Seyberth HW 1987 Tandem mass spectrometric determination of 11-dehydro-thromboxane $B_{2}$, an index metabolite of thromboxane $\mathbf{B}_{2}$ in plasma and urine. Anal Biochem 164:156163

7. Catella F, Nowak J, FitzGerald GA 1986 Measurement of renal and non-renal eicosanoid synthesis. Am J Med 81(suppl 2B):23-29

8. Catella F, Healy D, Lawson J, FitzGerald GA 1986 11-dehydro-thomboxane $B_{2}$ : a quantitative index of thromboxane $A_{2}$ biosynthesis in the human circulation. Proc Natl Acad Sci USA 83.5861-5865

9. Bunting S, Gryglewski R, Moncada S, Vane JR 1976 Arterial walls generate from prostaglandin endoperoxides a substance (prostaglandin $\mathrm{X}$ ) which relates strips of mesenteric and coeliac arteries and inhibits platelet aggregation. Prostaglandins 12:897-913

10. FitzGerald GA, Brash AR, Falardeau P, Oates JA 1981 Estimated rate of prostacyclin secretion into the circulation in normal man. J Clin Invest 68:1272-1276

11. Williams TJ, Peck MJ 1977 Role of prostaglandin mediated vasodilatation in inflammation. Nature 270:530-532

12. Seyberth HW, Kuhl PG 1988 The role of eicosanoids in pediatrics. Eur J Pediatr 147:341-349

13. Seyberth HW, Tulassay T, Kuhl PG, Soeding K, Rascher W, Schweer H 1988 Excretion of primary prostanoids and their metabolites during acute volume expansion. Prostaglandins 35:221-232

14. Tönshoff B, Momper R, Kühl PG, Schweer H, Schärer K, Seyberth HW 1990 Increased thromboxane biosynthesis in childhood hemolytic uremic syndrome. Kidney Int 37:1134-1141

15. Catella F, FitzGerald GA 1987 Paired analysis of urinary thromboxane $B_{2}$ metabolites in humans. Thromb Res 47:656-674

16. Reilly JAG, Doran J, Smith B, FitzGerald GA 1986 Increased thromboxane biosynthesis in a human model of platelet activation: biochemical and functional consequences of selective inhibition of thromboxane synthase. Circulation 73:1300-1309

17. Kühl PG, Bolds JM, Lloyd JE, Snapper J, FitzGerald GA 1988 Thromboxane $\mathrm{A}_{2}$ /prostaglandin endoperoxide receptor activation mediates bronchial and hemodynamic responses to endotoxemia in the conscious sheep. Am J Physiol 254:R310-R319

18. Kravis TC, Henson PM 1977 Accumulation of platelets at sites of antigenantibody-mediated injury: a possible role for $\operatorname{lgE}$ antibody and mast cells. $J$ Immunol 118:1569-1576

19. Patrono C, Ciabattoni G, Remuzzi G, Gotti E, Bombardieri S, Di Munno O, Tartarelli G, Cinotti GA, Simonetti BM, Pierucci A 1985 Functional significance of renal prostacyclin and thromboxane $A_{2}$ production in patients with systemic lupus erythematosus. J Clin Invest 76:1011-1018

20. Pierucci A, Simonetti BM, Pecci G, Mavrikakis G, Feriozzi S, Cinotti GA, Patrignani P, Ciabattoni G, Patrono C 1989 Improvement of renal function with selective thromboxane antagonism in lupus nephritis. $\mathrm{N}$ Engl $\mathrm{J}$ Med 320:421-425

21. Nowak J, FitzGerald GA 1989 Redirection of prostaglandin endoperoxide metabolism at the platelet-vascular interface in man. J Clin Invest 83:380

22. Higgs GA, Moncada S, Vane JR 1978 Prostacyclin reduces the number of slow moving leukocytes in hamster cheek pouch venules. J Physiol (Lond) 280:55P-56P

23. D'Humieres S, Russo-Marie F, Vargaftig BB 1986 PAF-acether induced synthesis of prostacyclin by human endothelial cells. Eur J Pharmacol 131:1319

24. Rossi V, Breviario F, Ghezzi P, Dejana E, Mantovani E 1985 Prostacyclin synthesis induced in vascular cells by interleukin-I. Science 229:174-176

25. Warren JS, Mandel DM, Johnson KJ, Ward PA 1989 Evidence for the role of platelet-activating factor in immune complex vasculitis in the rat. $\mathrm{J}$ Clin Invest 83:669-678

26. Bevilacqua MP, Pober JS, Wheeler ME, Cotran RS, Gimbrone MA 1985 Interleukin-I acts on cultured human vascular endothelium to increase the adhesion of polymorphonuclear leukocytes, monocytes, and related leukocyte cell lines. J Clin Invest 76:2003-2011

27. Turi S, Belch JJF, Beathie TJ, Forbes CD 1986 Abnormalities of vascular prostaglandins in Schonlein-Henoch purpura. Arch Dis Child 61:173-177

28. Larsen GL, Henson PM 1983 Mediators of inflammation. Annu Rev Immunol $1: 335-359$

29. FitzGerald DI, Roy L, Catella F, FitzGerald GA 1986 Platelet activation in unstable coronary disease. N Engl J Med 315:983-989

30. Reilly JAG, Roy L, FitzGerald GA 1986 Biosynthesis of thromboxane in patients with systemic sclerosis and Raynaud's phenomenon. $\mathrm{Br}$ Med J 292:1037-1039 